\title{
El legado filosófico-político del exilio español del 39
}

\author{
The philosophical-political legacy of Spanish exile of 1939 \\ Antolín SÁnchez Cuervo \\ Instituto de Filosofía-CCHS, CSIC
}

RESUMEN. El pensamiento político del exilio español de 1939 ofrece, setenta años después, perspectivas fecundas y actuales. Junto a una obra sistemática y bien conocida, ligada al marxismo crítico, como la de Adolfo Sánchez Vázquez, cabe destacar otras expresiones, de carácter fragmentado y sinuoso, en las que se centra este trabajo. Tales fueron, concretamente, la temprana genealogía del fascismo que apuntaron Eugenio Ímaz y María Zambrano valiéndose de claves hermenéuticas diferentes aunque coincidentes en ligar dicho fenómeno a la progresión secularizadora de la razón moderna. En segundo lugar, la memoria del propio exilio a la que tanto uno como otro apelaron a contrapelo de un presente autocomplaciente respecto a las victimas de su pasado mas reciente, suscitando así un debate entre la historia y la memoria impregnado de significación política. Y, en tercer lugar, la crítica de la lógica contractualista apuntada por Eduardo Nicol en el horizonte de un racionalismo tecno-científico global, cuyas implicaciones políticas no dejaron de afectar a la democracia española instaurada tras el fin del franquismo.

Palabras clave: Exilio español de 1939, política, guerra, fascismo, memoria, contractualismo.
Abstract. The political thought of the Spanish exile of 1939 offers, seventy years later, fruitful and current perspectives. Besides a systematic and well-known work, linked to critical Marxism, such as the one of Adolfo Sánchez Vázquez, include other expressions, fragmented and meandering character, which focuses this paper. These were, namely, the early genealogy of fascism pointed out by Eugenio Ímaz and María Zambrano using different hermeneutical keys, but overlapping in linking it to the secularizing progression of modern reason. Second, the memory of own exile to both appealed against a complacent present about the victims of his more recent past, thereby leading to a debate between history and memory impregnated of political meaning. And third, the critique of contractarian logic pointed out by Eduardo Nicol on the horizon of a global techno-scientific rationality whose political implications affected the Spanish democracy instituted after the dictatorship.

Key words: Spanish exile of 1939, politics, war, fascism, memory, contractualism. 
El legado filosófico del que fuera uno de los mayores exilios originados en la Europa del siglo XX ofrece, setenta años después, perspectivas fecundas, algunas de ellas muy actuales y otras insuficientemente exploradas aún. Trayectorias intelectuales como las de José Gaos, Eduardo Nicol, Joaquín Xirau, María Zambrano, Eugenio Î́maz, Adolfo Sánchez Vázquez, Juan David García Bacca o José Ferrater Mora, por citar solamente algunos de los nombres más conocidos, dejaron tras de sí contribuciones notorias - y en algunos casos, sumamente originales - a ámbitos y debates del pensamiento contemporáneo bien diversos. Tales fueron, entre otros, la problemática vigencia de la metafísica o las condiciones de posibilidad de la filosofía como tal, suscitando desde lecturas singulares del método fenomenológico hasta revisiones del lógos occidental que se remontaban a sus mismos orígenes. Ligado a lo anterior, la recepción crítica de corrientes filosóficas tales como el historicismo, la fenomenología, el vitalismo, el existencialismo o la filosofía analítica. Asimismo, la singularidad de la filosofía en lengua española y su actualidad en plena catástrofe europea y cuando las promesas de la racionalidad canónica moderna parecían del todo truncadas, fue un motivo inspirador relevante, contribuyendo de manera decisiva y substancial a la conformación de una comunidad iberoamericana de pensamiento y a la definición, madura y rigurosa, de un «pensar en español». Otra aportación significativa sería aquélla relacionada con la filosofía política, cuyas expresiones explícitas más relevantes estuvieron ligadas al socialismo, ya fuera éste entendido en un sentido «humanista» o distante del marxismo como en el caso de Luis Araquistáin y Fernando de los Ríos; o en clave abiertamente marxista, aun bajo una lente crítica distante de planteamientos dogmáticos o cientistas. Tal fue el caso de Adolfo Sánchez Vázquez, cuya obra, polémica hacia el «anti-humanismo» althusseriano y disidente respecto del «socialismo real», constituye la expresión más acabada y madura de este pensamiento político exiliado, aun cuando parte de la misma se centrara en problemas estéticos. Todo ello limitándonos a aquellas referencias más relevantes y prescindiendo de obras exiliadas cercanas a la reflexión política tales como la sociología de Medina Echeverría o la filosofía del derecho de Recasens Síches.

Pero, junto a estos planteamientos explícitos de lo político, cabría mencionar otros de carácter más fragmentado, implícito o sinuoso, y no por ello insignificantes. Tales fueron, por ejemplo, la temprana genealogía del fascismo que apuntaron Eugenio Ímaz y María Zambrano valiéndose de claves hermenéuticas diferentes aunque coincidentes en ligar dicho fenómeno a la progresión secularizadora de la razón moderna. $\mathrm{O}$, en segundo lugar, la memoria del propio exilio a la que tanto uno como otro apelaron a contrapelo de un presente autocomplaciente respecto a las víctimas de su pasado más reciente, suscitando así un debate entre la historia y la memoria impregnado de significación política. $\mathrm{O}$, en tercer lugar, la crítica de la lógica contractualista esbozada por Eduardo Nicol en el horizonte de un racionalismo tecno-científico 
global cuyas implicaciones políticas no dejaron de afectar a la democracia española instaurada tras el fin del franquismo. Detengámonos un momento en cada uno de ellos.

1. Tanto Eugenio Ímaz como María Zambrano fueron testigos directos del fascismo, que además combatieron durante los años de la guerra civil y en cuya lógica moderna se adentraron más allá de su singular concreción española. Si el conflicto español fue, de alguna manera, el primer episodio de la Segunda Guerra Mundial y el campo de pruebas del fascismo internacional ante una inminente campaña europea, había que trascender entonces el tópico cainita de las «dos Españas» y los moldes castizos del fascismo español para adentrarse en el meollo mismo de la racionalidad moderna. Ímaz incluso lo venía haciendo desde antes de 1936, al hilo del ascenso y la evolución del nazismo, con una singular agudeza que no dejaba de contrastar con la miopía de buena parte del intelecto español de entonces. En Cruz y Raya, Diablo Mundo y Revista de Occidente, retrató algunas de sus expresiones y ademanes, advirtiendo su voracidad política y su ciega voluntad de guerra, y trazando una sugerente hipótesis genealógica del mismo en tanto que consumación de todo un proceso de absorción secular de la religión desde las exigencias de la política moderna. Es relativamente conocido el humanismo utópico de Ímaz, quien buscó ciertas continuidades entre el erasmismo - una de sus grandes fuentes de inspiración-y referencias posteriores tales como la «volonté générale» de Rousseau, la «república-noumeno» de Kant e incluso la historicidad reconciliadora de Hegel ${ }^{1}$. Pero, al mismo tiempo, no dejó de advertir la ambigüedad de este pensamiento moderno y su sombría proyección al hilo de las razones de estado, la objetividad instrumental y una suerte de secularización bastarda. Por eso la Utopía de Moro y sus lectores novohispanos - apuntaba en Topía y utopía - se darían de bruces contra la Nueva Atlántida y el Novum Organum de Bacon. Esto es, contra el diseño de una contrautopía tecnocrática, ya barruntada en La ciudad del sol o en El Príncipe. La soberana e irreductible soledad con la que nace el hombre moderno tras la ruptura de la unidad religiosa que le coartaba y al mismo tiempo amparaba, y que el humanismo renacentista querrá reconducir, se traducirá entonces en una imparable obsesión por el poder que, teorizada por Bodino y el iusnaturalismo del XVII, encontrará formulaciones álgidas en el Leviatán: Hobbes absorberá y metabolizará secularmente los fanatismos causantes de las mismas guerras de religión de las que ese incipiente hombre moderno quería escapar, pero a costa del recurso a la fuerza como única garantía de paz y felicidad. Se prefigura ya, entonces, la guerra o el conflicto entre soberanías como esencia schmittiana de lo político, cuya justificación intrínseca última no residirá sino en el poder que emana de sí mismas. El pacto es entonces la fórmula secular

${ }^{1}$ Cf. «Topía y utopía», en Eugenio Ímaz. II. Topía y utopía, San Sebastián, Cuadernos universitarios, 1988, pp. 45-68. 
que ha logrado reducir las diversas ciudades de Dios a una sola ciudad secular, pero a costa del artificio leviatanesco; el mismo, por cierto, que Locke y Rousseau sólo quiméricamente habrían logrado desarmar y armar de otra manera, puesto que «la libertad del gobierno democrático liberal, lejos de restituir al hombre su libertad, lo que hace es abandonarle a la libertad de los demás, a la sociedad, que no es otra cosa que el sistema violento de las subordinaciones $(. ..) »^{2}$. La fe puritana en el trabajo y en la riqueza nacida de la tolerancia religiosa y madurada al hilo del expansionismo imperialista británico, y el dominio técnico sobre el mundo surgido del desencantamiento de la naturaleza inaugurado por Bacon y sistematizado bajo la categoría de progreso a partir de Turgot, entre otras referencias cruciales, irán haciendo el resto. Destreza técnica objetivada en la economía, proyección expansiva y justificación inmanente de sí misma en base a la lógica del progreso: la soberanía moderna, individual y colectiva, se instituye y fortalece creando ya las condiciones de posibilidad del estado totalitario.

Pero es en el idealismo en donde este proceso secularizador alcanzará momentos de síntesis particularmente maduros, bajo el sello del naciente nacionalismo germánico. Los Discursos a la nación alemana de Fichte - apunta Ímaz en «A Dios por razón de Estado» - instituyen «el santo patriotismo alemán» e instauran, en base a él, «todos los fervores de la patria terrenal» previa reducción pagana de la «patria celestial» significada en el cristianismo. Este último - afirma Ímaz citando a Fichte - identificaría a «la religión del tiempo viejo», lastrada por el «egoísmo» de los débiles, que necesitan el temor y la esperanza en un destino trascendente más allá de este mundo, y frente al cual se erige la «verdadera religión, que nuestra vida vive inmediatamente en Dios», y que «debe dominar en la época moderna». La substancia de esta religión moderna e inmanente, no es otra que la vida o espíritu del pueblo, expresión de lo eterno en la tierra y cuya afirmación paradigmática recaería en la nación alemana en tanto que «protopueblo» o Urvolk. La trascendencia inscrita en la libertad luterana de conciencia quedaba así reducida a una inmanencia colectiva y originaria que se exterioriza de manera ilimitada gracias a los resortes especulativos del idealismo. «Fichte no diviniza el Estado, pero sí, a través del espíritu del pueblo, el patriotismo. Ya es bastante».

Hegel hará el resto. Con Hegel, el contenido moral de esa vida espiritual se hace objetivo - y no sólo colectivo, racial o popular - en la medida en que se constituye como Estado. Éste es entonces «la realidad de la idea moral, o, si se quiere más claro, el paso de Dios por el mundo»; o acaso «el mismísimo demonio» ${ }^{3}$, pues ese paso mundano exige, no ya el sacrificio del individuo, sino también de todos aquellos pueblos o Estados que fracasen ante

2 «En busca de nuestro tiempo», en Eugenio Ímaz II. La fe por la palabra. Prólogo y edición a cargo de José Angel Ascunce Arrieta. San Sebastián, Cuadernos universitarios, 1988, p. 138.

3 Ibid., p. 45. 
el tribunal de la historia. Con Hegel, la razón se explica asimismo divinizándose, objetivándose en el Estado y realizándose históricamente merced a un autodespliegue dialéctico que reduce a mera apariencia la violencia de sus propios costes. Merced, asimismo, a la interioridad luterana, dicha realización se cumple sólo en aquellos Estados que han madurado religiosamente bajo el impulso de la Reforma y que son en consecuencia aptos para ser libres. En los países protestantes «el espíritu empapa inmanentemente lo secular», y esa interioridad, que inicialmente «era una vía de escape al otro mundo, se ha convertido en un camino circular, inmanente, dentro de la conciencia totalitaria del Estado» ${ }^{4}$ y de su epifanía en la historia. «El espíritu, por fin, después de un forcejeo dialéctico de milenios, ha llegado, en magnífico orto, a reconocerse a sí mismo como libre, como libertad. La historia, en realidad, ha terminado». Como en el mito - apunta Ímaz en «En busca de nuestro tiempo»- su último capítulo habría de escribirse «con sangre» ${ }^{5}$.

Precisamente a la sombra de Hegel, la escuela histórica e historiadores del Imperio germánico como Heinrich von Treitschke le sacarán todo su jugo al «espíritu del pueblo». En «A Dios por razón de Estado», advierte Ímaz la actualidad de este historiador nacionalista y antisemita en la Alemania nacional-socialista, particularmente en la efervescencia de sus movimientos político-religiosos. En primer lugar, el de los «cristianos alemanes» o «de raza aria» ${ }^{6}$, declarado en abril de 1933 bajo la apelación a la misión providencial que está llamado a desempeñar en el momento histórico actual, y cuyas directrices fundamentales propugnan la instauración de «una Iglesia a tono» con la «nueva soberanía del Estado nacional-socialista», frente a las amenazas del «bolchevismo y el anti-cristiano pacifismo» ${ }^{7}$. Pero más aún el llamado movimiento «acristiano», muy presente en la academia alemana y que, en la «línea pagana» ${ }^{8}$ de Fichte y Hegel, aquilatada por un cierto Nietzsche, culminaría la moderna interpretación «derrotista» del cristianismo, absorbiendo su fuerza moral para metabolizarla en una suerte de "religión germánica» ${ }^{9}$. Es en este contexto que Ímaz señala la actualidad de Treitschke, quien en su Politik (1897) justificaba la voluntad de poder del Estado en tanto que expresión misma de la voluntad de Dios. «Con Treitschke, el Espíritu Santo, la Palabra, es el Poder». Se culmina así, mediante una inversión de los términos, el proceso secularizador abierto por Lutero. Si con su doctrina de la justificación de los actos por la fe el padre de la Reforma había dejado a la conciencia prisionera de la palabra de Dios, ahora ésta «resulta prisionera de la conciencia», es decir, del soberano, entendido — afirma Ímaz a propósito de un dis-

\footnotetext{
4 Ibid., p. 145.

5 Ibid., pp. 142 y ss.

6 Ibid., p. 39.

7 Ibid., p. 41.

8 Ibid., p. 46.

9 Ibid., p. 43.
} 
curso reciente de Hitler- como imposición de un señorío que «no debe ser arbitrariedad, sino noble razón» y evidencia moral de las más altas capacidades y los más altos pensamientos; o, sencillamente, como «derecho del más fuerte». La palabra, prisionera entonces «de una camisa. De una camisa de fuerza. De una fuerza de 3.000.000 de camisas» ${ }^{10}$.

María Zambrano planteó un diagnóstico explícito del fascismo en la primera parte de Los intelectuales en el drama de España, ensayo de 1937, escrito por tanto en plena guerra. Su gran antecedente filosófico sería asimismo el idealismo, en tanto que construcción falsificadora de un saber absoluto o una inteligencia incondicional que explica y desarrolla, por sí misma y de manera autosuficiente, mediante categorías especulativas, la consistencia racional del mundo. Una inteligencia que excluye por tanto «otras realidades no racionales (...) que en determinados instantes parecen cubrir el horizonte del hombre como una gran tormenta de la que no se ve el fin», y que son «las que en realidad mueven su instrumento racional, le dirigen y orientan hacia una finalidad a veces enmascarada». Para Zambrano, el idealismo habría construido una racionalidad que soslaya y reprime la realidad humana radical, generando por ello una mala conciencia o un estado de adolescencia permanente en el que esa idealidad choca permanentemente con «la riqueza dispar de la realidad», impidiendo así una auténtica experiencia de ella. En este sentido, la gran consecuencia del idealismo no habría sido otra que un marchitamiento de la vida o una «sedimentación de sueños, deseos oscuros, desilusiones no formuladas, requerimientos incumplidos, que van aumentando» ${ }^{11}$; la generación de una cultura que, «por una parte, impide al hombre vivir íntegramente una experiencia total de su vida, al no reconocer la realidad y, por otra, ofrece una máscara en la que esconderse, salvando las apariencias todavía con una cierta comodidad.» De ahí su carácter profundamente contradictorio, generador de de una «enemistad con la vida» de la que el fascismo será expresión brutal. El fascismo es por ello «la desesperación impotente de hallar salida a una situación insostenible», fruto de un rencor europeo en aumento y de la incapacidad creadora de la burguesía. Es aferramiento violento al enmascaramiento idealista de la realidad, ya resquebrajado bajo la presión y el resentimiento de una vitalidad estancada que pugna por desahogarse. De ahí la instrumentalización degradada que el fascista hace de «conceptos sin vida ya, de cosas que han sido y han dejado de servir», su retórica hueca, ampulosa y grandilocuente, su delirio en medio de «ideas de ideas, entre pálidas sombras

10 Ibid., pp. 47 y ss. Esos 3.000.000 de camisas aluden a «los tres millones de luchadores» que «se han organizado como portadores de la dirección política de la nación (alemana: ASC)» (p. 48), según un fragmento de la Filosofía de la sociedad de Othmar Spann, traducida por el propio Ímaz (Madrid. Revista de Occidente, 1933).

11 Los intelectuales en el drama de España. Cf. M. Zambrano, Los intelectuales en el drama de España y escritos de la guerra civil, presentación de Jesús Moreno Sanz, Trotta, Madrid, 1998, p. 92. 
de creencias, entre restos de grandezas» ${ }^{12}$, con los que envuelve y disfraza una vitalidad resentida que se retuerce a sí misma al no poder expresarse y de cuya negación se alimenta, al mismo tiempo, esa idealidad degradada. Fascismo, en definitiva, es huida «sistemática y encubierta» de una realidad que persiste bajo la forma del resentimiento y que por tanto sólo puede aplacarse mediante su aniquilación. Por eso «Todo fascismo acaba en matar, en querer matar lo que no se quiere reconocer» ${ }^{13}$. Ha nacido «de la impotencia del idealismo europeo para superarse, de la enemistad europea con la vida, de su adolescencia marchita y estancada. Es incompatible el fascismo con la confianza en la vida; por eso es profundamente ateo» ${ }^{14}$.

La tesis fundamental de Zambrano sobre el fascismo, que tan sucintamente acabamos de exponer, parece muy diáfana. Pero, ¿qué significa que el fascismo sea «profundamente ateo»? ¿Por qué Zambrano identifica la «enemistad con la vida» con el ateísmo, o con cierto ateísmo al menos?

Si reubicamos esta breve pero jugosa reflexión de Zambrano contenida en Los intelectuales en el drama de España en el horizonte conceptual de un libro fundamental en su trayectoria como El hombre y lo divino (1955), cabría interpretar el idealismo - y su desenlace fascista - como el último episodio del proceso transformador de lo sagrado en divino que para Zambrano identifica al mismo despliegue de la racionalidad occidental, desde sus balbuceos bajo la configuración mitológica de los dioses griegos y de la poesía trágica. Expresión culminante del idealismo, la obra de Hegel cerraría el círculo trazado por este desarrollo, portentoso pero frustrante, pues su desenlace no sería otro que la disolución de lo divino en un saber absoluto o en un dios del conocimiento que absorbe y subyuga la vida, o la emancipación de lo humano respecto de lo divino, que al mismo tiempo hereda alimentándose de él. Es decir, el deicidio y la construcción de un superhombre productor incesante de víctimas ante su necesidad permanentemente insatisfecha de endiosamiento. O, como planteará Zambrano en Persona y democracia (1958) - libro en cierto sentido «gemelo» de El hombre y lo divino - la necesidad de una «historia sacrificial», cuya exasperación dará lugar al absolutismo — «nudo trágico de la historia de Occidente»—, entendido como «una caída, un abismo que se abre en la historia, y que devora alucinatoriamente siglos enteros (...) sumiéndola en una situación pre-histórica, más bien infra-histórica, como ha sucedido en Europa en el período que acaba de transcurrir»; pues bajo «las ideologías totalitarias» — prosigue-

«transcurría este proceso de endiosamiento, de regreso a través de unos hombres y un pueblo a ese nivel en que el hombre devora al hombre literalmente. (...) Y como este endiosamiento no puede jamás cumplirse, necesita la reno-

\footnotetext{
12 Ibid., p. 94.

13 Ibid., p. 103.

14 Ibid., p. 95.
} 
vación continuada de las víctimas; la víctima innumerable. Es el momento en que la historia es simplemente un crimen multiplicado alucinatoriamente; (...).» 15

Esa «víctima innumerable» identificará para Zambrano el retorno de lo sagrado, entendiendo por tal el fondo hermético y opaco de la realidad, el contacto ilegible con una realidad oscura e impenetrable que envuelve y agobia a la conciencia, dejándola en una situación de extrañeza radical; el fondo último de la realidad aún no codificado bajo las categorías de lo divino, las cuales habrían ido marcando la evolución del pensamiento filosófico occidental hasta su fallida consumación bajo el idealismo. Para Zambrano, la disolución de lo divino bajo este último ha provocado una reaparición de lo sagrado bajo la experiencia de la nada, entendida como «el vacío» o la gran resistencia en la que ha encallado el «vivir desde la conciencia» o desde la actividad inmanente y autoconsciente del «Espíritu». La nada es por ello «lo irreductible que encuentra la libertad humana cuando pretende ser absoluta. (...) Es lo sagrado que reaparece en su máxima resistencia. Lo sagrado con todos sus caracteres: hermético, ambiguo, activo, incoercible. (...) El vacío, la negación que colabora con el ser y le sirve. (...) Lo sagrado puro, la absoluta mudez que corresponde a la ignorancia y al olvido de la condición humana: ser libre, activo, más padeciendo». ${ }^{16}$ Para Zambrano, idealismo y nihilismo serán en realidad dos expresiones sólo aparentemente contrapuestas del mismo fenómeno - la disolución de lo divino-, de la misma manera que el superhombre nietzcheano no sería sino una réplica del superhombre dibujado por Hegel. Lo sagrado es el fondo irreductible que asoma tras esta disolución. De ahí su significación nihilista y su sublimación fascista.

El idealismo como racionalización destructiva de la vitalidad y como deicidio deificador son por tanto dos caras del mismo proceso. De esta manera, el fascismo, en tanto que agitación violenta y suicida de esa vitalidad resentida, no sería otra cosa, a la luz de El hombre y lo divino, que la manifestación brutal de lo sagrado en su retorno. El fascismo tendría así una connotación «sagrada» o de «religión del mal» bajo la que se banaliza y justifica por sí misma toda transgresión de la dignidad humana, y se define lo político a partir de la beligerancia y la guerra. Por eso decía Zambrano que es «profundamente ateo» y no un ateísmo más desenmascarador de la tendencia deificadora inscrita en la tradición filosófica. Es ateo en el sentido de que niega radicalmente cualquier posibilidad transformadora de lo sagrado en lo divino - $\mathrm{O}$ lo que es igual en términos zambranianos, cualquier posibilidad de una experiencia humana - . De ahí la identificación del fascismo con lo sagrado y su textura nihilista. La inteligencia fascista se retuerce contra la vida porque

15 Persona y democracia, Madrid, Siruela, 1996, pp. 92s.

16 El hombre y lo divino. Prólogo de M. ${ }^{a}$ Fernanda Santiago Bolaños. Madrid, FCE, 2007, pp. 179s. 
«flota en el vacío», porque reacciona contra «la nihilidad que le rodea» ${ }^{17}$. Para Zambrano, el fascismo sería en definitiva la expresión brutal y colectiva de un hermetismo sagrado que ha retornado bajo la inconsistencia de la nada. Esa brutalidad, materializada en el apoyo militar ítalo-germánico al golpe de 1936 y mistificada con el singular fascismo español — de raíz tradicionalista y reaccionaria, ajeno a todo idealismo secularizador - es la que para Zambrano habría aplastado el "proyecto de hombría» ${ }^{18}$ alumbrado en los años republicanos.

2. Tanto Ímaz como Zambrano reivindicaron, por otra parte, una memoria del propio exilio a contrapelo del olvido en que éste se veía sumido tras el triunfo del fascismo en España con la complicidad de las democracias occidentales. En este sentido discurrían varios artículos de Ímaz en la emblemática revista España peregrina, editada en las primeras horas del exilio republicano en México. "Discurso in partibus», publicado en el primer número, suscitaba la posibilidad de una segunda derrota, esta vez bajo el olvido que habían propiciado tanto los intelectuales de la «tercera España» - los «liberales desarbolados», según la amable expresión de Jordi Gracia ${ }^{19}$ - como los estrategas de la alta diplomacia europea. «El combate se ha perdido. ¿Y la verdad?», se preguntaba Ímaz ante la nueva batalla, de signo hermenéutico, que ahora comenzaba y en la que las tensiones entre historia y memoria, en tanto que dos maneras distintas de pensar el pasado de las víctimas, estaban llamadas a dirimirse. «Porque lejos de ser, como se dice, la Historia maestra de la vida» — proseguía Ímaz-

«es la vida maestra de la Historia. Preguntad a los intelectuales españoles que han hecho la guerra si la historia que saben ahora la supieron antes. Dadles un libro cualquiera de historia, de los consagrados por el refrendo de las academias y la recomendación de los eruditos, de Historia de España o de Historia Universal, de historia eclesiástica o profana, económica, cultural, y veréis cómo se les cae de las manos, sino de la boca, como un vómito. (...) ¿No es, precisamente, cuando la verdad está tan cerca que nos salpica sangrientamente a la cara, no es entonces cuando tenemos la verdadera distancia, la que ella nos ahonda en la conciencia? ¿Entonces qué?» ${ }^{20}$

17 «Los intelectuales en el drama de España», op. cit., p. 103.

18 Ibid., p. 96.

19 Aquellos que, confundiendo el proyecto democratizador de la Segunda República con las turbulencias revolucionarias que lo afectaron, cedieron a la tentación de adherirse discretamente al golpe militar de Franco, asimismo confundido con una excepcionalidad violenta pero pasajera que luego daría paso a una progresiva restauración de políticas liberales. Contrariamente a semejantes expectativas, de cuya honestidad Ímaz siempre dudó, el régimen instaurado tras la guerra resultaría más bien intimidatorio y amedrentador para estos «liberales desarbolados»: Ortega, Azorín, Baroja, Marañón, Pérez de Ayala... Sobre estos últimos, cf. Jordi Gracia: La resistencia silenciosa. Fascismo y cultura en España, Anagrama, Barcelona, 2004, pp. 67-115.

${ }^{20}$ Eugenio Ímaz II. Topía y utopía, op. cit., pp. $17 \mathrm{~s}$. 
Ímaz sugería así una doble e irreconciliable mirada sobre la guerra y sus consecuencias. Por una parte, aquélla que tiende a justificarla en términos civilizadores. El sacrificio de la República y el inminente olvido de los muertos y exiliados que ha generado es entonces el precio a pagar por la continuidad de la cultura y la civilización, tal y como ésta se refleja en aquellos discursos que recogen el pasado con una prudente «distancia de siglos» - o dicho de otra manera, con «objetividad»guerra y el exilio como una experiencia de inhumanidad que pone al descubierto la barbarie inscrita en esa conciencia histórica de civilización y que deposita en el recuerdo de sus víctimas la expectativa de un presente diferente. Si la primera mirada sintoniza con el paradigma ilustrado del «espectador» y con la llamada «frialdad burguesa», la segunda lo hace con el testimonio, capaz de leer los acontecimientos de su época con «la verdadera distancia» que le otorga esa experiencia — aquélla que deja la cara salpicada de sangre-, y que corre el peligro de quedar sepultada bajo aquella distancia de siglos. Es por ello - apuntillaba Ímaz - que «si no recobramos el hilo de la verdad que teníamos, estamos perdidos, muertos, más que muertos, para que nos coman en vida los gusanos» ${ }^{21}$.

Zambrano retomaba ese mismo hilo en su «Carta sobre el exilio» de 1961, en plena travesía de desierto y cuando las expectativas de una caída del régimen franquista se habían disuelto completamente. Por eso los destinatarios de esta carta no eran tanto los enemigos de antaño como los «anticonformistas de hoy, los que no aceptan el régimen, denomínense de una $\mathrm{u}$ otra manera»; aquellos que, coincidiendo con el arribo a la vida pública de nuevas generaciones de tecnócratas, consideran «que la suerte y destino de España deben estar y estarán determinados sólo por la acción y aun por el pensamiento de ellos, los que están en España». Estos inconformistas piden al exiliado que deje de serlo y regrese, que renuncie a su exilio "hasta el punto de casi ignorarlo, olvidarlo y desconocerlo», pues para ellos «el exiliado ha dejado de existir ya, vuelva o no vuelva» ${ }^{22}$. Quieren que el pasado que encarnan sea eliminado y se confunda con el presente. En sintonía con esa historia sacrificial que el fascismo había llevado hasta sus últimas consecuencias, piensan esos inconformistas que el fin de la dictadura sólo puede lograrse en términos de progreso o de continuidad. Es decir, al margen de un pasado que, por muy interpelador que sea, no cabe en un presente que sólo debe mirar hacia el porvenir, guiado por las élites que han encontrado acomodo en él y condicionado por los compromisos entre las viejas y las nuevas generaciones. Esos inconformistas - apunta Zambrano en un borrador de la carta en cuestión - quieren en definitiva «eliminarnos del pasado

${ }^{21}$ Eugenio Ímaz II. Topía y utopía, op. cit., p. 21. Una contraposición entre las miradas sobre la realidad que adoptan el espectador y el testigo puede encontrarse en Reyes Mate: $\mathrm{Me}$ moria de Auschwitz. Madrid, Trotta, 2003, capítulos 4 y 5.

${ }^{22}$ Cuadernos del Congreso por la Libertad de la Cultura (París), n. ${ }^{\circ} 49$, p. 68. 
como hace más de veinte años se nos arrojó del porvenir que creyeron comenzaba», pues al igual que en un rito primario, «para que se diera este porvenir hacía falta una hecatombe, el sacrificio de todos los que pudieron llevar en forma apreciable y visible un rasgo visible de aquella España, entonces a sumergir, a abismar para siempre.» ${ }^{23}$

Contra la aniquilación de ese pasado que el exilio se llevó consigo y que desde su latencia cuestiona la normalidad del presente, se rebela la memoria zambraniana; y no para realizar anacrónicamente ese pasado truncado, ni para substanciarlo en términos de revancha o venganza - aun cuando el resentimiento de las víctimas sea algo legítimo y no sólo nocivo o indeseable-, sino más bien para liberar al presente de su indigencia e interrumpir, mediante el recuerdo de esas víctimas, su médula sacrificial. En sintonía con la filosofía benjaminiana de la historia, la memoria zambraniana suscita la posibilidad de un encuentro fecundo entre la vitalidad latente de un pasado desplazado y la indigencia enmascarada de un presente autocomplaciente. Persigue por ello el desencantamiento del hechizo de la guerra bajo el que aún viven tanto los partidarios del régimen como sus críticos de adentro, detenidos, todos ellos, en «una trágica coherencia, (...) la coherencia de la fatalidad no vencida, del fatum no superado.» Un «fatum» que ha naturalizado a las víctimas haciéndolas invisibles o reduciéndolas a un daño colateral, inevitable e insignificante. Frente a la historia naturalizada, Zambrano reivindica un pasado que, al desprenderse del decurso de esa historia, al despojarse de sus razones y justificaciones, se ha quedado suspendido, reducido a una suerte de presencia pura y diáfana, de pasado que no pasa, aguardando que alguien lo reciba y despierte su potencial crítico latente. Zambrano advierte así que el secreto del presente reside en la actualidad de ese pasado velado bajo el olvido y significado en el exilio. Por eso el exiliado está más cerca «de ser criatura de la verdad que personaje de la historia» y se ha quedado al borde de la misma, "en el lugar sin nombre donde han estado siempre todos los dejados, por siglos a veces, para que alguien los recoja. (...) Y está así, embebido en paz y sosiego infinito, en un indecible olvido, porque no se ha quedado para que lo salven a él (...), sino para que quien lo recoja en el momento en que deba ser, reciba algo que sólo él tiene» ${ }^{24}$. Por eso el exiliado no pide otra cosa «sino que le dejen dar, dar lo que nunca perdió y lo que ha ido ganando: la libertad que se llevó consigo y la verdad que ha ido ganando en esta especie de vida póstuma que se le ha dejado» ${ }^{25}$. Por eso la «pacificación del presente» nunca vendrá «del porvenir», sino «del pasado, de los muertos, de los enterrados y semienterrados vivos», $\mathrm{y}$ «en forma muy específica del exiliado:

23 «El exiliado», Roma, 18 de enero de 1961. Fundación María Zambrano. Documentos manuscritos pertenecientes al archivo de María Zambrano, caja n. ${ }^{\circ}$ 2, M-157.

24 «Carta sobre el exilio», pp. 67ss.

25 Ibid., p. 70. 
ese que vive en el aire - del aire también - y es al par un enterrado vivo, en cierto modo una representación de la Antígona, el símbolo de la conciencia sepultada viva. (...) Sí: Antígona o el fin de la Guerra Civil.» ${ }^{26}$

3. El fin de la dictadura y el advenimiento de la transición democrática no impidió que esta apelación política a la memoria del propio exilio siguiera vigente. Los abundantes, diversos y a veces enconados matices que la revisión de dicho proceso transicional y sus consecuencias ha suscitado en los últimos años son sin duda muy numerosos. Pero difícilmente se puede obviar hoy que la transición, sin perjuicio de sus bondades, discurrió conforme a los criterios de una Ley de Punto y Final que amnistió tanto a víctimas como verdugos, que dio a luz a la democracia en la estela del franquismo, o que estigmatizó la memoria republicana bajo el sello del resentimiento, aun cuando esto último se simultaneara con una progresiva desmitificación de la memoria de los vencedores. No en vano la persistencia de la memoria republicana: la propia Zambrano apelaba en 1977 a un «presente activo que lleva consigo todo lo que fue presente por la verdad sostenida, respirada»; por un «entonces» que «sigue siendo todavía por haber sido vivido tan verdaderamente, sin regateo alguno» y que es «razón germinativa, germinante en lo escondido de la historia» ${ }^{27}$. Sánchez Vázquez señalaba asimismo el doble y contradictorio punto y final del exilio que significó la transición, como cancelación histórica del mismo, pero también como instauración de un olvido cuyo calado aún se dejaba notar casi tres décadas después ${ }^{28}$. Los ejemplos podrían multiplicarse. Pero, detengámonos un momento en un breve escrito de Eduardo Nicol publicado en 1991, hacia el final de su vida bajo el elocuente título de «La fase culminante del desencanto», el cual resulta doblemente significativo. En primer lugar, por su carácter excepcional, ya que Nicol siempre había eludido el motivo personal, circunstancial o autobiográfico, no ya como fuente de reflexión filosófica - inepta, a su juicio, para encauzar la aspiración universal del lógos-, sino también como un medio de comunicarse con el público. Este breve escrito autobiográfico rompía, sin embargo, dicho silencio, precisamente para hablar de la República, la guerra, el exilio y la España actual. En segundo lugar, porque el desencanto que manifiesta ante el nuevo panorama democrático en España bien podría remitirnos a la crítica de la tecnificación de la política y de la lógica contractualista que había esbozado en libros relativamente recientes, concretamente en El porvenir de la filosofia (1972) y La reforma de la filosofía (1980).

El desencanto era en todo caso muy explícito. La nueva democracia - afirmaba Nicol tras evocar la envergadura del proyecto cultural, político y educativo de la República-

26 «El exiliado», op. cit.

27 Prólogo de 1977 a Los intelectuales en el drama de España, op. cit., pp. 77-87.

28 «El doble fin del exilio del 39», en Claves de la razón práctica: 133 (junio 2003). 
«ha venido sin pena ni gloria, y ha restaurado la antiquísima disputa de los políticos: sin idea del hombre español, ni proyecto de vida nacional. En suma, sin paideia. (...) Esperábamos que ahora ese fervor que produce sentirse repentinamente libres produciría entre los españoles un nuevo renacimiento. Lo que se produjo fue una explosión de grosera pornografía, y el más trivial de los afanes: el de ganar dinero deprisa y como sea. (...) No muestra su vigor la ilustre ley de vida que es el humanismo. Adiós España, por segunda vez. (...) España, que era rica en educadores, se encuentra hoy privada de ellos.»

Para el gobernante español de ahora — proseguía_-, la democracia significa «organizar las elecciones, equilibrar la balanza de pagos, vestirse de senor para asistir a las reuniones internacionales, y disimular su ignorancia con el ropaje de la solemnidad.» 29

Aun de manera escueta y desairada, Nicol ponía el dedo en la llaga al identificar la restauración de la democracia con una cultura del simulacro que reducía la política a espectáculo y tecnificación instrumental, y el bien común a individualismo masificado o industria de masas; rasgos que, más allá del contexto español, el propio Nicol había diagnosticado en los libros anteriormente mencionados, confiriéndoles un carácter global bajo el nuevo totalitarismo de la «razón de fuerza mayor»: una razón que ha dejado de orientarse hacia el conocimiento de la realidad, y con ello hacia la construcción de un horizonte práctico-comunitario, para someterla con vistas a su aprovechamiento utilitario e individualizado. Bajo esta razón nueva, «que es ciega y muda frente al ser, aunque muy lúcida frente al ser-cosa» — había dicho Nicol en El porvenir de la filosofía- la ciencia deja de ser una vocación libre para reducirse a una técnica productiva y mecanizada, regida en cuanto tal por la necesidad insatisfecha de su propia ilimitación y objetivada en una praxis irreflexiva e instrumental: «ser» equivaldrá entonces a «ser útil», de la misma manera que «verdad» será aptitud para la dominación y «realidad» aquello destinado a ser explotado. ${ }^{30}$

Nicol rastreaba los orígenes de esta razón naturalizada en el contrasentido de una ciencia que, a partir, ya, del giro utilitario que recibe a manos de Ba$\operatorname{con}^{31}$ y a tono con la nueva sociedad de propietarios dominante en la política moderna, comienza a desvanecerse a medida que progresa en términos técnicos y que incrementa su poderío sobre el mundo. Se trata por tanto de una razón abocada a la irracionalidad y la contradicción hasta el punto de reducirse a una lógica instrumental, substantiva, ciega, anónima, uniforme y puramente biológica, sin otro fin que la pura funcionalidad mediática ni otras consecuencias que una deshumanización global; o que un predominio de la utilidad que

${ }^{29}$ Eduard Nicol: semblança d'un filosof. Edició a cura d'Angel Castiñeira. Barcelona, Acta, Fundació per a les idees i les arts, 1991, p. 93.

30 El porvenir de la filosofía, México, FCE, 1972., p. 238

31 Cf. La reforma de la filosofía, México, FCE, 1980, pp. 46-61. 
Nicol no vacila en denominar «totalitario» ${ }^{32}$, pues bajo la coacción de ese predominio se ve el hombre obligado a «reducir a una sola todas las direcciones de su mirada» y «a una sola dimensión la realidad toda» ${ }^{33}$. Bajo esta servidumbre totalitaria, la necesidad desplaza a la libertad y la subsistencia a la existencia, pues el hombre moderno ha generado artificialmente nuevas dependencias que le oprimen y de las que no puede desligarse. La erosión de la naturaleza por la técnica se ha extendido a las propias relaciones entre los hombres, sufriendo éstas todo un proceso de cosificación.

La principal clave genealógica, en lo que a política se refiere, de esta razón de fuerza mayor no sería otro que la devaluación del principio comunitario bajo la lógica contractualista. Nicol identificó aquel principio con el pensamiento político del humanismo español - especialmente el de Francisco Suárez-, mismo que resurgiría con extraordinaria actualidad bajo el proyecto republicano de $1931^{34}$. Una concepción moral del Estado, basada en la comunidad natural de los individuos, orientada hacia el bien común y responsable de garantizar la dignidad de la persona, habían sido los rasgos fundamentales de ese humanismo político, finalmente desplazado - había apuntado Nicol en tres ensayos de los años cuarenta ${ }^{35}$ - por la tradición contractualista iniciada, sobre todo, por Locke. A partir del filósofo inglés, ya no será la dignidad de la persona sino la propiedad aquello que el Estado está llamado a garantizar, a la manera además de un contrato que sella la renuncia del individuo a su estado natural y su ingreso coercitivo en la sociedad. Desprovisto de cualquier finalidad moral, el Estado tiende entonces a reducirse a una figura policial, susceptible de benevolencia tanto como de soborno. Para Nicol, tal será, a grandes rasgos, la fórmula moderna del bien común, con la que se intenta acotar el absolutismo de príncipes y de reyes al hilo de la nueva y emergente conciencia burguesa. Una fórmula que, como igualmente señalara Ímaz, subordina el todo a las partes y no al contrario. Devaluada en una sociedad de propietarios, la comunidad perderá entonces su sentido de la alteridad y su dimensión ético-política originarios en favor del principio del interés y la competencia, dominante tanto en el ámbito nacional como internacional. «El pensador contractualista» - afirma Nicol en este sentido- extrae de la individualidad real del hombre, comunitaria por definición,

32 El porvenir de la filosofía., p. 21.

33 Ibid., p. 38.

34 Para Nicol, «el gran proyecto» enarbolado por la Segunda República era «único en la historia política europea del siglo XX» por la conjunción de política y educación, pensamiento y acción, gobierno y creación de cultura, que había conseguido alumbrar. Hacía posible «una paideia nueva» bajo «una responsabilidad común». Cf. Eduard Nicol: semblança d'un filosof, op. cit., p. 88.

35 Cf. «Libertad y comunidad. La filosofía política de Francisco Suárez», «Propiedad y comunidad. Suárez frente a Locke y Marx» y «La rebelión del individuo», en Eduardo Nicol: La vocación humana, México, Consejo Nacional para la cultura y las artes, 1953, Presentación de Enrique Hülsz, pp. 246-292. 
la noción ideal de un ente que sería ontológicamente más perfecto en su individualidad si no tuviera vínculos constitutivos; y que estaría por lo tanto metafísicamente autorizado, en su existencia efectiva, a regatear en el cumplimiento de su contrato: los vínculos serían ataduras, la comunidad sería lo que interfiere con la libertad. Y así, de esa idea abstracta e irreal del individuo, nace el individualismo moral y político. ${ }^{36}$

Es decir, a partir de una abstracción arbitraria — el individuo aislado—-, se justifican el interés pragmático de cada cual y el vínculo coactivo que supone su inserción en un supuesto - e igualmente abstracto - interés general, como las grandes piedras angulares de un consenso aparentemente democrático abocado, en realidad, a una «guerra global». La devaluación de esos mismos vínculos comunitarios que el contractualismo sólo cumple en términos de especie o meramente biológicos, regidos por el instinto de subsistencia, desemboca finalmente en una cultura de la dominación y la guerra. Con la imposibilidad de una vida comunitaria — prosigue Nicol_- hemos llegado «al todos sin integrar a cada uno» ${ }^{37}$, lo cual significa el fin de la libre reciprocidad y de la propia historicidad humana en tanto que fundamentos de toda praxis, y la sustitución de todo ello por una «violencia uniforme» ${ }^{38}$. La reciprocidad comunitaria transmuta así en lucha de especie, el orden social en interdependencia biológica, la vocación de universalidad en fatal uniformidad. Al hilo de la globalización tecnológica, ambos rasgos «coinciden con el más violento desorden» ${ }^{39}$ y con una cultura belicista que absorbe los ámbitos de la existencia hasta el punto de que todo «se promueve y se juzga en relación con la guerra: la religión, la ciencia, el arte, el deporte, la filosofía y hasta la vida privada. En la nueva cultura, todo ha de contribuir a la victoria y está permanentemente movilizado.» El prójimo es entonces «el adversario por principio»y todos los adversarios «no son más que comparsas en este gran suceso que es la conversión de la guerra en protagonista de la historia ${ }^{40}(\ldots)$. El campo de batalla parece ser el semblante de los hombres: la violencia es su rasgo más saliente ${ }^{41}$. (...) Todos los hombres son, propiamente, heridos de guerra» ${ }^{42} \mathrm{y}$ todos «estamos en guerra, cualesquiera que sean los regímenes» ${ }^{43}$.

Estas últimas citas de Nicol pueden recapitular de alguna manera este somero recorrido por algunos fragmentos del pensamiento político exiliado del 39. Ni el fin de la guerra que asoló España y Europa entre 1936 y 1945 supu-

36 El porvenir de la filosofía, op. cit., p. 84. El «pacto social, es un artificio del racionalismo. Presupone en el individuo un estado de soberanía que no existe», afirma en la p. 83.

37 Ibid., p. 86.

38 Ibid., p. 84.

39 Ibid., p. 87.

40 Ibid., p. 52.

41 Ibid., p. 49.

42 Ibid., p. 132.

43 Ibid., p. 124. 
so el fin de la guerra como forma de vida, ni la derrota del fascismo impidió la pervivencia del totalitarismo en la política occidental durante las décadas posteriores. Quizá una de las aportaciones más significativas y actuales de este pensamiento político sea la conciencia, lúcida y sombría, de tales continuidades, dibujadas sobre el trasfondo de las herencias deshumanizantes de una secularización irresuelta, de los olvidos de la historia entendida como una racionalización del pasado y de la lógica contractualista y pragmático-instrumental que recorre la política moderna. 